\title{
Alcohol consuming habits and its effect on adherence and blood glucose level in type 2 diabetes mellitus
}

\author{
R Maskey \\ Assistant Professor, Department of Internal Medicine, BPKIHS
}

Dear Editor,

First of all I would like to congratulate Dr. Bijay Thapa for addressing neglected issues like adherence of oral hypoglycemic agents in patients with type 2 diabetes and especially concerning on alcohol consumption and its effect on blood glucose.

It is expected that between 2000 and 2030 there will be $37 \%$ increase in the worldwide prevalence of diabetes. ${ }^{1}$ Besides aging of the population, family history of diabetes, genetic predisposition, lack of physical activity and high-energy intake leading to overweight and obesity have been shown to be largely responsible for this epidemic. ${ }^{2}$ Among five lifestyle behaviors moderate consumption of alcohol could be attributed to the lack of adherence in $91 \%$ of new type 2 diabetics. ${ }^{3}$ So I agree with the conclusion made by the author that alcohol has played a significant role in non- adherence. But since there are other factors responsible for non-adherence, I think it should also be mentioned in this study.

Several epidemiological studies have suggested an inverse association between moderate alcohol consumption and reduced risk for type $2 \mathrm{DM} .{ }^{4}$ In a recent randomized controlled trial in women without diabetes, alcohol consumption of $30 \mathrm{~g} /$ day was shown to have beneficial effects on insulin and triglyceride concentrations. ${ }^{5}$ But in this study alcohol quantity is mentioned in drinks per day, if it was in gram per day then it would have been easy to counsel patients on basis of quantity. Moreover in our community we also have besides wine, whisky and beer we also have ghad, rakshi, tomba having different percentage of alcohol.

\section{References}

1. Wild S, Roglic G, Green A, Sicree R, KingH: Global prevalence of diabetes: estimates for the year 2000 and projections for 2030. Diabetes Care 27:1047-1053, 2004.

2. Zimmet P, Alberti KG, Shaw J: Global and societal implications of the diabetes epidemic. Nature 414:782-787, 2001.

3. Hu FB, Manson JE, Stampfer MJ, Colditz G, Liu S, Solomon CG,Willett WC: Diet, lifestyle, and the risk of type 2 diabetes mellitus in women. $\mathrm{N}$ Engl J Med 345: 790-797, 2001.

4. Stampfer MJ, Colditz GA, Willett WC,et al.A prospective study of moderate alcohol drinking and risk of diabetes in women.Am J Epidemiol. 1988; 128:549- 558.

5. Davies MJ, Baer DJ, Judd JT, Brown ED, Campbell WS, Taylor PR: Effects of moderate alcohol intake on fasting insulin and glucose concentrations and insulin sensitivity in postmenopausal women: a randomized controlled trial. JAMA 287: 2559-2562, 2002. 